Esculentoside A (EsA) is a saponin isolated from the roots of Phytolacca esculenta. Previous experiments have shown that it has strong antiinflammatory effects. Tumour necrosis factor (TNF) is a very important inflammatory mediator. It is known that there are two types of TNFTNF $\alpha$ is from macrophages/monocytes and TNF $\beta$ is from activated lymphocytes. In order to study the mechanism of the anti-inflammatory effect of EsA, it was determined whether TNF $\alpha$ production from human peripheral monocytes was altered by EsA under lipopolysaccharide (LPS)-stimulated conditions. EsA was found to decrease TNF $\alpha$ production in a dose-dependent manner at concentrations higher than $1 \mu \mathrm{mol} / 1$ EsA. Recent studies have shown that EsA has a curative effect on chocolate cyst and other inflammatory diseases. Our previous studies have shown that EsA could reduce the release of platelet activating factor (PAF) from rat macrophages, and inhibit interleukin-1 and interleukin-6 production from murine macrophages. The reducing effects of EsA on the release of TNF $\alpha, I L-1, I L-6$ and PAF may explain its anti-inflammatory effect.

Key words: Esculentoside A, Human peripheral monocyte, Tumour necrosis factor $\alpha$

\section{Inhibitory effect of esculentoside A on tumour necrosis factor $\alpha$ production by human monocytes}

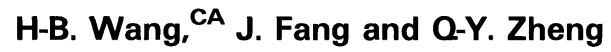

Department of Pharmacology, College of Pharmacy, Second Military Medical University, Shanghai 200433, People's Republic of China

${ }^{\mathrm{CA}}$ Corresponding Author

\section{Introduction}

Esculentoside A (EsA) is a saponin isolated from the root of Pbytolacca esculenta, and is identified as: 3-O-[ $\beta$-D-glucopyranosyl-(1-4)- $\beta$-Dxylo-pyranosyl] phytolaccagenin. The structure of this compound is shown in Fig. 1. Experiments have shown that it has strong anti-inflammatory effects. ${ }^{1}$ It is now known that tumour necrosis factor (TNF) possess a number of properties of inflammatory response. ${ }^{2,3}$ Platelet activating factor (PAF), interleukin-1 and interleukin-6 are also inflammatory mediators. ${ }^{3}$ It has been shown that EsA inhibited the production of PAF by $\mathrm{A}_{23187}$ stimulated rat macrophages, ${ }^{4,5}$ and the production of TNF $\alpha$, IL-1, IL- 6 of LPS stimulated murine peritoneal macrophages. ${ }^{6,8}$ The aim of this work was to evaluate the effects of EsA on the production of TNF $\alpha$ by LPS stimulated human peripheral monocytes.

\section{Materials and Methods}

Reagent: RPMI-1640, lipopolysaccharide (Escherichia coli $055: \mathrm{B} 5)$ and calcimycin $\left(\mathrm{A}_{23187}\right)$ were purchased from Sigma (USA).

Human peripheral monocyte preparation: Human monocytes were isolated by a combina- tion of Ficoll-Hypaque gradient centrifugation and centrifugal elutriation. This procedure yielded populations of monocytes with greater than $95 \%$ purity. The cells were washed three times in RPMI-1640 and suspended at $1 \times 10^{6}$ cells per $1 \mathrm{ml}$ in freshly prepared standard culture medium. The cells were plated at $1 \mathrm{ml}$ of cells per well.

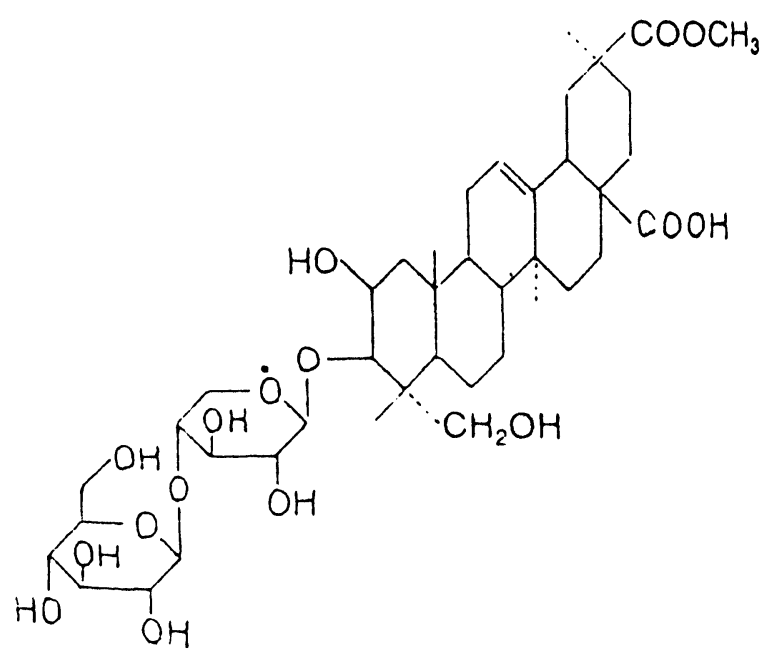

FIG. 1. The structure of esculentoside A 
TNFo production: Two hours later, the medium containing non-adherent cells was decanted and the non-adherent cells in supernatant were counted to measure the adherence ratio. TNF $\alpha$ activity was expressed as $\mathrm{U} / 10^{6}$ monocytes. The adherent cells were rinsed twice with Hanks's solution. Then the adherent cells were incubated with $\mathrm{A}_{23187}(1 \mu \mathrm{mol} / \mathrm{l})$ for $6 \mathrm{~h}$. After incubation, the medium was discarded, and the cells were washed three times with RPMI-1640 to remove $\mathrm{A}_{23187}$. Fresh culture medium without serum was added to every well with lipopolysaccharide (LPS, $10 \mu \mathrm{g} / \mathrm{ml}$ ) in the presence or absence of EsA. The cultures were incubated in a humidified atmosphere of $5 \% \mathrm{CO}_{2}$ and at $37^{\circ} \mathrm{C}$ for another $6 \mathrm{~h}$. The supernatants were harvested and centrifuged. The cell-free supernatants were collected, dialysed in phosphate-buffer solution for $24 \mathrm{~h}$, and stored at $-20^{\circ} \mathrm{C}$ prior to activity assay.

TNFo production assay: TNFa assay was performed essentially as described by Kunkel et al. ${ }^{5}$ with minor modifications. Briefly, $\mathrm{L}_{929}$ cells (50000/well) were dispensed into 96-well flatbottomed microtitre plates in a volume of 0.1 $\mathrm{ml} /$ well. The following day, the cells were incubated for $18 \mathrm{~h}$ in the presence of $1 \mu \mathrm{g}$ of actinomycin D and serial 1:2 dilutions of test sample. Media were then decanted, and the remaining cells in each well were stained with crystal violet for about $15 \mathrm{~min}$, washed with tap water, and dried at $40^{\circ} \mathrm{C}$. Absorbance of the cells in each well was read using a microenzyme linked immunosorbent autoreader. Units of TNF $\alpha$ activity were defined as described by Kunkel et $a l^{5}$

Cell viability: The trypan blue exclusion test was performed after $6 \mathrm{~h}$ incubation with or without EsA. Cell viability was also determined by measuring lactate dehydrogenase ( $\mathrm{LDH}$ ) activity in the cell-free supernatants according to the method of Beutle.?

Statistics: Each experiment was carried out at least three times. Values were expressed as the mean \pm standard error. Variation between parallel experiments was less than 30\%. Probability values for statistical differences were determined by Student's $t$-test and $p$ values of less than 0.05 were considered significant.

\section{Results}

Effects of ESA on production of TNFa from buman monocytes: TNF $\alpha$ in the supernatant after being dialysed was assessed by the killing of $\mathrm{L}_{929}$
Table 1. Effect of esculentoside A on tumour necrosis factor $\alpha$ production from $10^{6}$ human peripheral monocyte stimulated by LPS $10 \mu \mathrm{g} / \mathrm{ml}$ mean $\pm \mathrm{SD}, n=3$ samples

\begin{tabular}{lc}
\hline & TNF $\alpha$ activity $\left(\mathrm{U} / 10^{6}\right)$ \\
\hline LPS & $51.4 \pm 4.6$ \\
LPS+EsA $(\mu \mathrm{mol} / \mathrm{I})$ & $55.0 \pm 13.5$ \\
0.01 & $45.2 \pm 8.9$ \\
0.1 & $36.5 \pm 3.6^{\star}$ \\
1.0 & $27.1 \pm 6.1^{*}$ \\
10.0 & \\
\hline
\end{tabular}

${ }^{*} p<0.05$ versus control group.

cells. One unit of TNF $\alpha$ was defined as the reciprocal of the dilution of a preparation that results in $50 \%$ survival of the cells. The results are presented in Table 1 . It is observed that the decrease of TNF $\alpha$ production was significant at the concentrations of 1 and $10 \mu \mathrm{mol} / 1 \mathrm{EsA}$.

Effects of EsA on the kinetics of TNF production from buman monocytes: Monocytes were cultured in LPS $(10 \mu \mathrm{g} / \mathrm{ml})$ with or without EsA, and the supernatants were harvested at $2 \mathrm{~h}$ intervals. TNF $\alpha$ activity can be detected after $2 \mathrm{~h}$ exposure to LPS. Figure 2 shows that TNF $\alpha$ production by human monocytes were inhibited in a time dependent manner by EsA at a concentration of $5 \mu \mathrm{mol} / 1$.

Effects of EsA on cellular activity: In order to eliminate the possibility that EsA was toxic for the cells tested, cell viability was monitored by measuring $\mathrm{LDH}$ activity in the supernatant and by the trypan blue exclusion test performed at the end of the macrophage culture. Results of the

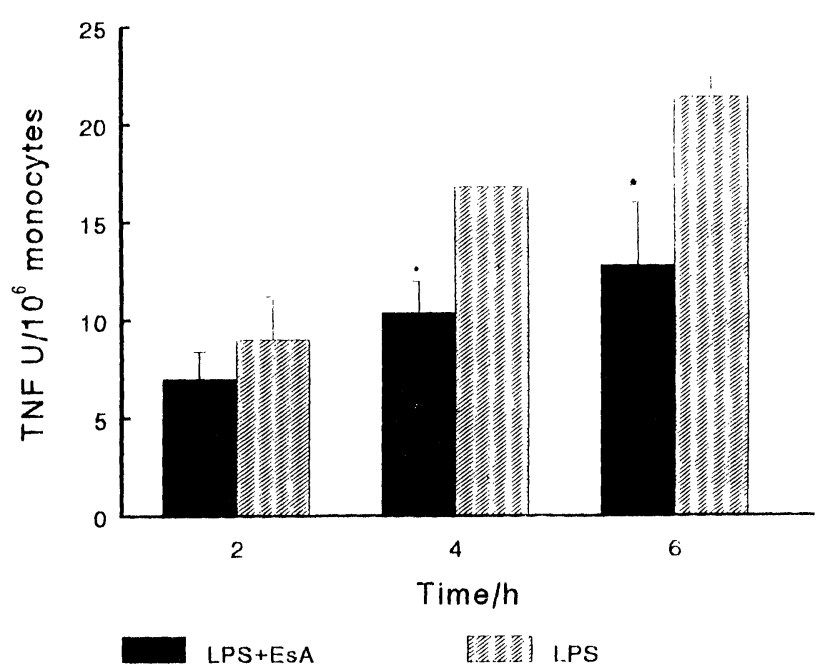

FIG. 2. Effect of EsA on the kinetics of TNF $\alpha$ production in supernatants from human peripheral monocytes stimulated with 10 $\mu \mathrm{g} / \mathrm{ml}$ LPS for 2, 4 and $6 \mathrm{~h}$. The concentration of EsA was 5 $\mu \mathrm{mol} / \mathrm{l}, n=3$, mean $\pm \mathrm{SD},{ }^{*} p<0.05$ versus LPS. 
Table 2. LDH activities in supernatants and cell viability ratio of human peripheral monocytes treated with or without esculentoside A. $n=3$ samples, mean $\pm \mathrm{SD}$

\begin{tabular}{ccc}
\hline & LDH activity $(\mathrm{U} / \mathrm{ml})$ & Cell viability ratio (\%) \\
\hline Control & $4.35 \pm 0.17$ & $>99$ \\
EsA ( $\mu \mathrm{mol} / \mathrm{I})$ & & \\
0.01 & $4.47 \pm 0.19$ & $>99$ \\
0.1 & $4.29 \pm 0.14$ & $>99$ \\
1.0 & $4.55 \pm 0.16$ & $>99$ \\
10.0 & $4.44 \pm 0.35$ & $>99$ \\
\hline
\end{tabular}

$\mathrm{LDH}$ in supernatant of adherent macrophages, cultured for $6 \mathrm{~h}$ with various concentrations of EsA, was not different from that of the control, as is shown in Table 2. Cell viability was confirmed by the trypan blue exclusion test. The cell viability ratio in test samples was more than 99\% (Table 2). The result was the same as previously reported. ${ }^{10}$

\section{Discussion}

In this study, EsA induced a dose-dependent decrease in the TNF $\alpha$ concentrations measured in the supernatant of LPS-stimulated human monocytes. The kinetics of TNF $\alpha$ production were also changed. TNF was initially identified as a factor that appeared in the circulation of animals following the injection of endotoxins. TNF $\alpha$ is a product of stimulated monocytes and macrophages, but it is also produced by keratinocytes. ${ }^{6}$ In addition to the cytotoxic activities of TNF $\alpha$ in some types of transformed cells, recent data have shown that TNF $\alpha$ mediated stimulation of collagenase synthesis and prostaglandin $\mathrm{E}_{2}$ $\left(\mathrm{PGE}_{2}\right)$ production by synovial cells, ${ }^{7}$ and stimulated bone resorption and inhibition, ${ }^{8}$ suggesting that TNF $\alpha$ might be an important mediator of inflammation. Platelet activating factor (PAF) is a mediator of anaphylaxis and inflammation; it plays an important role in inflammation, and there is cooperation between PAF and TNF $\alpha$ in inflammatory reactions. ${ }^{11}$ It has been found that EsA reduced release of PAF from rat macrophages. A previous study also showed that EsA can inhibit the inflammatory reaction induced by carrageenan. ${ }^{1}$ Recent clinical trials showed that a Chinese herb containing EsA had a significant curative effect on chocolate cyst. Our recent test showed that EsA could significantly inhibit IL-1 and IL- 6 production from murine macrophages. ${ }^{12}$ Thus, together with the present investigation it is suggested that the anti-inflammatory effects of EsA might be due to its reducing effects on the release of TNF $\alpha$, PAF, IL-1, IL- 6 and other inflammatory mediators.

\section{References}

1. Zheng QY, Mai $\mathrm{K}$, Pan XF. Antiinflammatory effects of esculentoside $\mathrm{A}$. Chin J Pharmacol Toxicol 1992; 6: 221-224.

2. Dinarello CA, Mier JW. Lymphokines. New Engl J Med 1987; 317: 940945.

3. Maestre P, Zarco C, Guerrero CG. Cooperation between tumor necrosis factor (TNF) and platelet-activating factor (PAF) in the inflammatory response. J Lip Med.1990; 2: s151-s159.

4. Fang J, Zheng QY. Inhibitory effects of esculentoside $\mathrm{A}$ on platelet activating factor released from calcimycin induced rat peritoneal macrophages. Acta Pharmaceutica Sin 1991; 26: 721-724.

5. Kunkel SL, Spengler M, May MA, Spengler R, Larrick J, Remick D. Prostaglandin $\mathrm{E} 2$ regulates macrophages-derived tumor necrosis factor gene expression. J Biochem 1988; 263: 5380-5384

6. Dinarello CA. Cytokines: Interleukin-1 and Tumor Necrosis Factor (Cachectin). New York: Raven Press, 1988: 54.

7. Dayer JM, Beutler B, Ceram A. Cachectin/tumor necrosis factor stimulates collagenase and prostaglandin $\mathrm{E}_{2}$ production by human synovial cells and dermal fibroblast. J Exp Med 1985; 162: 2143-2168.

8. Bertolini DR, Nedwin GE, Bringman TS, Smith DD, Mundy GR. Stimulation of bone resorption and inhibition of bone formation in vitro by human tumor necrosis factor. Nature 1986; 319: 516-518.

9. Beutle E. Lactate Debydrogenase. 2nd edn. New York: Grune \& Stratton, 1975, 63-64.

10. Fang J, Zheng QY, Wang HB, Yi YH. Effects of esculentoside A on tumor necrosis factor production by mice peritoneal macrophage. Mediators of Inflammation 1992; 1: 375-377.

11. Braquet P, Braquet MP, Bourgaain QH, Bussolin F, Hosford D. PAF/ cytokin auto-generated feedback networks in microvascular immune injury: consequences in shock, ischemia and graft rejection. J Lip Med 1989; 1: 75-112.

12. Ju DW, Zheng QY, Wang HB, Fang J. Effect of esculentoside A on immune function in mice. Acta Pharmaceutica Sin 1994; 29: 252-255.

Received 10 June 1996;

accepted in revised form 17 July 1996 


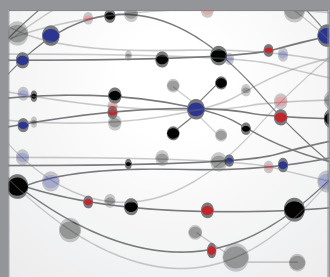

The Scientific World Journal
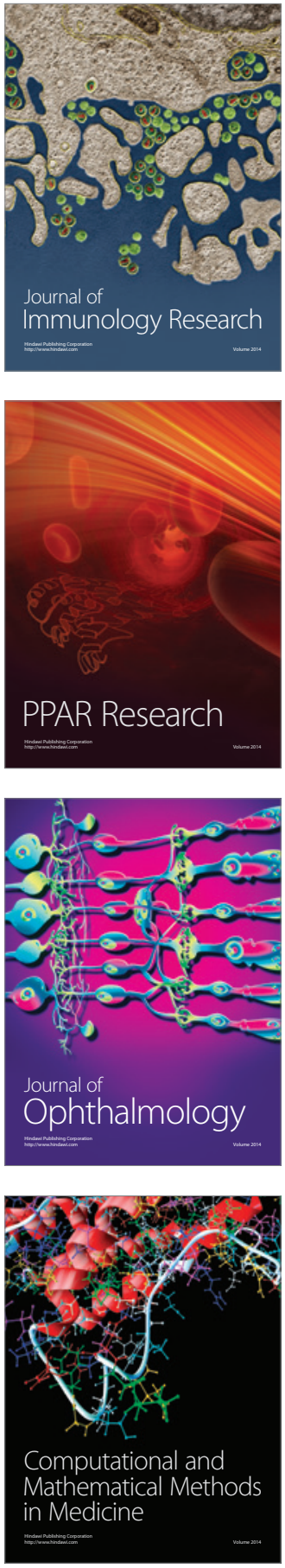

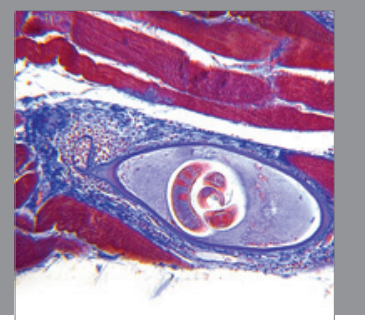

Gastroenterology

Research and Practice
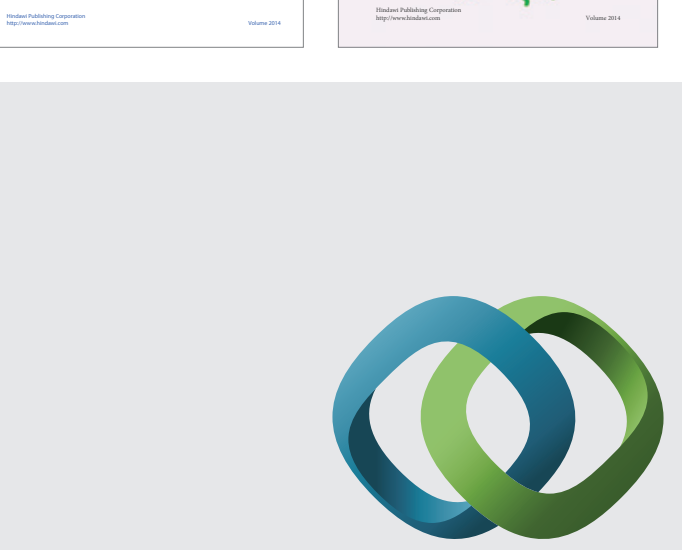

\section{Hindawi}

Submit your manuscripts at

http://www.hindawi.com
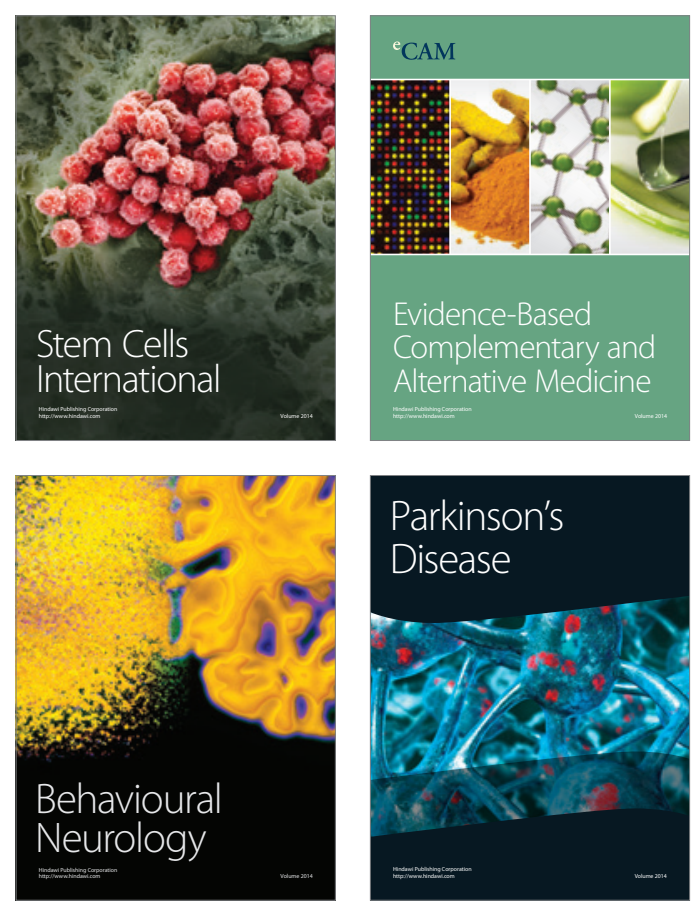

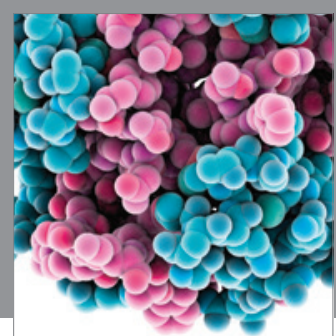

Journal of
Diabetes Research

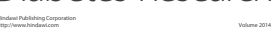

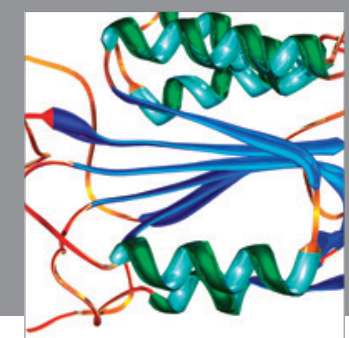

Disease Markers
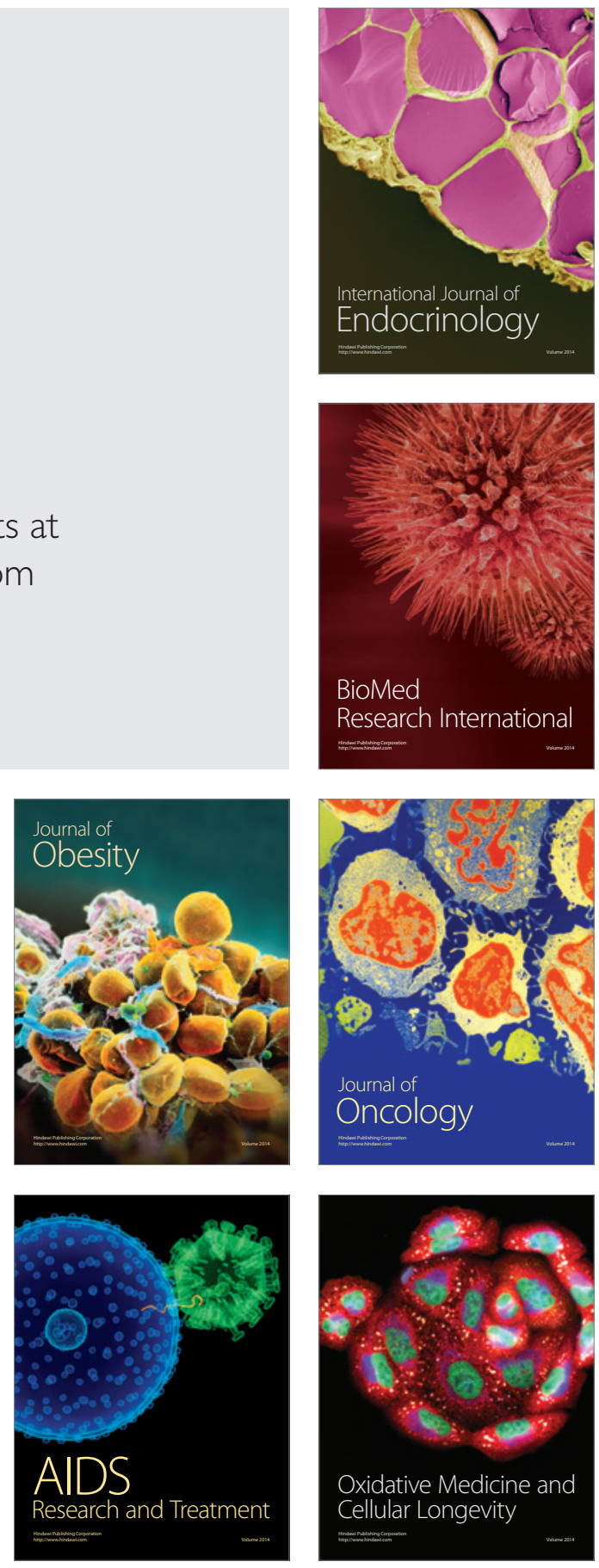